\title{
Arithmetical estimation under conditions of different payoff matrices
}

\author{
AMIA LIEBLICH and ISRAEL LIEBLICH, The Hebrew \\ University of Jerusalem, Jerusalem, Israel
}

A forced-choice arithmetical estimation task was devised. The task included three units of 50 addition problems each. To each unit of the task a different payoff matrix was attached. Twenty Ss participated in the experiment. It was found that estimation under severe time limits was correct in about $70 \%$ of the items. No effects of the different payoff matrices was found. Ss showed perfect probability matching in their estimation behavior.

Arithmetical ability can be measured in two principal ways. In the more conventional method, the $S$ is required to compute the result of an arithmetical problem and state his answer in an open-end or forced-choice form. A second method, which may be of interest, is the requirement to estimate the result of an arithmetical problem under severe time pressure such that no systematic computation is possible. This aptitude of correct estimation could be of importance in several real-life situations when a decision is based on a prompt evaluation of the possible outcomes, i.e., dynamic bargaining situations, logistic decisions under time-stress, etc. Tasks of arithmetical estimation may be of two different kinds: (a) the production of estimated results when the components of the problem are presented; or (b) the acceptance or rejection of a given result to a presented problem. The reported study investigated the second kind of arithmetical estimation, which may be named forced-choice arithmetical estimation (FCAE).

When a problem of FCAE is presented, a 2 by 2 stimulus-response matrix is defined, producing four possible stimulus-response contingencies, i.e., hit, correct rejection, false positive, or miss (Swets, Tanner, \& Birdsall, 1964). The reported study dealt with the possibility that different payoff matrices may lead to different distribution of the responses falling under the four possible contingencies mentioned above.

\section{SUBJECTS}

Ten research assistants in the Department of Psychology participated in the pretest. Twenty undergraduate students participated in the experiment.

\section{INSTRUMENTS}

A FCAE test was constructed. This test included three units of 50 addition problems each. Each problem was comprised of six three-digit numbers and their sum, which was correct in $50 \%$ of the problems and incorrect in the rest. The incorrect items had a mean deviation of 500 from the correct result, and the distribution of deviations was approximately normal, with a standard deviation of 50 . In each section of the test the problems appeared in random order.

\section{PROCEDURE}

A pretest was conducted to determine the minimal time needed for exact computation of the addition problems. In the pretest all Ss needed more than $9 \mathrm{sec}$ for the computation, so it was decided to limit the estimation time per trial to $5 \mathrm{sec}$.

In the experiment, each $S$ was individually tested in three testing conditions in one session. The order of the conditions was rotated for each $S$ to control for order effects.

The different conditions ( $\mathrm{A}, \mathrm{B}$, and $\mathrm{C}$ ) were defined by the different payoff matrices ( $A, B$, and $C$ ) which appear in Table 1.

The numbers in the payoff matrices represent Israeli agorot ( $\mathrm{S}$ could gain in $1 / 2 \mathrm{~h}$ a maximum of 5.5 Israeli pounds, in comparison to 3.5 Israeli pounds which was the E's fee per
Table 1

Payoff Matrices Defining the Three Experimental Conditions

\begin{tabular}{|c|c|c|c|c|c|c|}
\hline \multirow[t]{2}{*}{ Payoff matrix } & \multicolumn{2}{|c|}{$\mathbf{A}$} & \multicolumn{2}{|c|}{$\begin{array}{c}\text { B } \\
\text { Estimate } \\
\end{array}$} & \multicolumn{2}{|c|}{ C } \\
\hline & correct & $\begin{array}{l}\text { in- } \\
\text { correct }\end{array}$ & correct & $\begin{array}{l}\text { in- } \\
\text { correct }\end{array}$ & correct & $\begin{array}{l}\text { in- } \\
\text { correct }\end{array}$ \\
\hline sum $\begin{array}{l}\text { correct } \\
\text { incorrect }\end{array}$ & $\begin{array}{l}+3 \\
-1\end{array}$ & $\begin{array}{l}-1 \\
+3\end{array}$ & $\begin{array}{l}+5 \\
-1\end{array}$ & $\begin{array}{l}-1 \\
+5\end{array}$ & $\begin{array}{l}+1 \\
-5\end{array}$ & $\begin{array}{l}-1 \\
+5\end{array}$ \\
\hline
\end{tabular}

hour). The following instructions were read to $S$ : "This is an experiment on arithmetical estimation. You will be asked to decide whether the sum printed under each problem is correct or incorrect. Half of the sums are correct and the other half incorrect. You will have $5 \mathrm{sec}$ for your decision; therefore, you will not be able to compute the sum, only to estimate it." After these instructions the payoff matrix for the first condition was explained. The E signaled every $5 \mathrm{sec}$, and Ss put down their estimations. After each 50-item section, i.e., payoff condition, $\mathrm{E}$ computed with $\mathrm{S}$ the amount gained or lost in this section.

\section{RESULTS}

All the estimates of Ss were combined for each condition. The empirical stimulus-response matrices are presented in Table 2. Inspection of the individual S-R contingency matrices indicated that four Ss out of 20 showed a shift of more than $5 \%$ in the proportion of the negations in Condition C, as compared to their proportion of negations in Conditions A or B.

\section{DISCUSSION}

The combined results of the hits and correct rejections show that Ss performed efficiently on the arithmetic estimation task. More than $70 \%$ of their estimates were correct, i.e., identified the correctness or incorrectness of the sums.

It is of interest to note that performance on this task as measured by the combined number of hits and correct

Table 2

The Empirical Distribution of S-R Contigencies

\begin{tabular}{|c|c|c|c|}
\hline Condition & correct & $\begin{array}{c}\text { A } \\
\text { Estimate } \\
\text { incorrect }\end{array}$ & total \\
\hline \multicolumn{4}{|l|}{ sum } \\
\hline correct & 357 & 143 & \multirow{3}{*}{$\begin{array}{l}500 \\
500\end{array}$} \\
\hline incorrect & 143 & 357 & \\
\hline Total & 500 & 500 & \\
\hline \multirow[t]{2}{*}{ Condition } & \multicolumn{3}{|c|}{$\begin{array}{c}\text { B } \\
\text { Estimate }\end{array}$} \\
\hline & correct & incorrect & total \\
\hline \multicolumn{4}{|l|}{ sum } \\
\hline correct & 357 & 143 & \multirow{3}{*}{$\begin{array}{l}500 \\
500\end{array}$} \\
\hline incorrect & 138 & 362 & \\
\hline Total & 495 & 505 & \\
\hline \multirow[t]{3}{*}{ Condition } & \multirow{2}{*}{\multicolumn{3}{|c|}{$\underset{\text { Estimate }}{\mathrm{C}}$}} \\
\hline & & & \\
\hline & correct & incorrect & total \\
\hline \multicolumn{4}{|l|}{ sum } \\
\hline correct & 366 & 134 & \multirow{3}{*}{$\begin{array}{l}500 \\
500\end{array}$} \\
\hline incorrect & 141 & 359 & \\
\hline Total & 507 & 493 & \\
\hline
\end{tabular}


rejections was not influenced by the different incentives presented in the payoff matrices of Conditions $A$ and B. In spite of the fact that in Condition $B$ the expected gain was higher than in Condition $A$, no improvement was found in the efficiency of the estimation.

Assuming a model of rationality, which would state that $S$ tends to maximize his expected gains, it could be hypothesized that Matrix $\mathrm{C}$ would produce relatively more negations as compared to the proportion of negations produced in Conditions A and B. Table 2 shows clearly that this is not the case. The individual data also showed only four Ss who shifted towards more negations in Condition $C$ relative to their behavior in Conditions A and B. This lack of "rationality" is especially interesting in the reported study, since the "rational" decision rule could be easily applied by $S$ without any further computations. It is claimed (Miller, Kaplan, \& Edwards, 1967), that lack of "rationality" could be attributed to the difficulty in computing the expected gains of different alternatives. However, the reported study used a simplified task in which a "rational" decision rule was applicable. But, even in this simple case, Ss did not respond to payoff Mátrix C in the "rational" way.

One explanation to this phenomenon could be lack of subjective discrimination between the monetary values in Matrices A, B, and C. This is, of course, an ad hoc explanation, but it could point to a reversed application of the model of maximization of expected gains. On the assumption that Ss behave according to such a model, this model could be used to compute the subjective value of the entries in the payoff matrix for a certain individual. In these terms, it could be stated that for most Ss the values of 3 and 5 agorot fall into one subjective category. This suggestion could be of use in ambiguous decision situations, where the subjective values of different alternatives need clarification. In the reported study, it seems that motivation to succeed was more important to Ss than the monetary rewards, although they were substantial. It is interesting that this motivation operated while Ss performed anonymously.

Finally, attention should be called to the total lack of response bias, i.e., yea-saying vs nay-saying, in the answers of Ss, in spite of the fact that the estimation task was partially a guessing task (Rorer, 1965). This is apparent in the sums of columns in Table 2 . In other terms, there was a striking probability matching. The component of probability estimation in the decision process of this task does not seem to be affected by the severe time restriction. It is only the very simple gains computation which are thus affected.

\section{REFERENCES}

MILLER, L. W., KAPLAN, R. J., \& EDWARDS, W. JUDGE: A value judgment-based tactical command system. Organizational Behavior \& Human Performance, 1967, 2, 1-25.

RORER, L. G. The great response-style myth. Psychological Bulletin, $1965,63,129-156$

SWETS, J. A., TANNER, W. P., JR., \& BIRDSALL, T. G. Decision processes in perception. In J. A. Swets (Ed.), Signal detection and recognition by human observers. New York: Wiley, 1964. Pp. 3-57. 